\title{
The Prevalence of Ovine Gastro Intestinal Nematode and Associated Risk Factor in Jigjiga Woreda, Fafan Zone, Somali Regional State, Eastern Ethiopia
}

\author{
Abdi Mohammed ${ }^{1}$ and Nigussu Fasil ${ }^{2 *}$ \\ ${ }^{1}$ College of Veterinary Medicine, Jigjiga University, Ethiopia \\ ${ }^{2}$ Assistant professor, Hawassa university, Ethiopia
}

Submission: February 28, 2019; Published: March 25, 2019

*Corresponding author: Nigussu Fasil, Assistant professor, Faculty of veterinary Medicine, Hawassa university, Ethiopia

\begin{abstract}
A cross-sectional study was conducted from November 2015 to April 2016 in jijiga Woreda, Eastern Ethiopia Somali regional state with the impartial of determining the prevalence and associated risk factors with ovine gastro intestinal nematode infestation. There was collected 384 fecal samples were examined using flotation technique and Mcmaster techniques. Out of the total sampled collected 257 (66.9\%) sheep had a gastrointestinal nematode infection. A parasitological investigation was showed that sheep in the study area were verminous by a variety of helminthic nematodes. Out of total gastro intestinal nematodes Strongyle were the most frequently 210 (54.6\%) recovered nematode eggs followed by mixed 20 (5.2\%), Strongyloides18 (4.7\%),and Trichuris species 9 (2.3\%).The eggs per gram (EPG) count was determined using McMaster technique showed that $91(35.4 \%)$ of the sheep were lightly infested, 90 (35\%) moderately infested and 76 (29.5) heavily infested. There was a statistically significant difference between age, body condition scores and season $(p<0.05)$ with prevalence and eggs per gram (EPG) counts but there was no significant among with the sex. The study revealed that statistically significant difference $(p>0.05)$ was not found in prevalence among the six Peasant association, in general the study was showed that Gastrointestinal nematodes are one of the major problems that could impede health and productivity of sheep in the study area. Hence, emphasis should be given for public awareness instituted in the study area, in order to effective strategic treatment, the control and prevention of gastrointestinal nematode infection with further studies on species identification and larval ecology.
\end{abstract}

Keywords: jijiga woreda; Prevalence; Ovine; Nematode

Abbrevations: ${ }^{\circ} \mathrm{C}$ : Degree Celsius; BCS: BODY Conditions score; CSA: Central Statical Authority; EPG: Egg Peg Gram; FAO: Food and Agriculture Organization; Km: Kilo Meter; L: Larvae; MM: Millimeter; No.: Number of Variable; PAS: Peasent Associations; Spp: Species; SPSS: statistical package for social science; SORPARI: Somali Regional Pastoral And Agro-Pastoral Research Institute; X2: Chi-Square Test

\section{Introduction}

Sheep and goats are the most numerous of man's domesticated livestock and are especially important in more extreme climates of the world. Over two-thirds of the total population of sheep and goats occur in the less developed countries where they often provide major contribution to farming enterprises [1]. Livestock systems in developing countries were described by rapid change, driven by factors such as population growth, increases in the demand for livestock products as incomes rise and urbanization. Livestock currently subsidize about 30 percent of agricultural gross domestic product in developing countries [2] and is becoming the profligate growing sub-sector of agriculture [3]. Africa hosts 205 and 174 million sheep and goats representing $17 \%$ and $13 \%$ of the world total small ruminant population, respectively.
The population of small ruminants in sub-Saharan Africa has estimated to be 274 million [4].

The population of livestock found in Ethiopia was expected that 53.4 million cattle, 25.5 million sheep and 22.78 million goats [5]. Ethiopia is the second in Africa, and the sixth in the world, in terms of sheep population. In spite of enormous population and importance of small ruminants, the country has benefited little from this enormous resource owning to a multitude of problems like poor nutrition, poor animal production systems, reproductive inefficiency, management constraints, lack of veterinary care, and disease being the most important. Disease alone accounts for mortality of $30 \%$ in lambs and $20 \%$ in adults [6]. 
Helminthes infections in small ruminants are serious problems in the developing world, particularly where nutrition and sanitation are poor. Gastro intestinal nematode infection is one of the major health problems in the world. In developed world, the greatest component of impact by these nematode parasites was possibly found in the cost of control. However, their influence is greater in the sub-Saharan Africa in general and Ethiopia is particular due to ecological factors suitable for diversified hosts and parasite species [7]. Nematode parasites of small ruminants are primarily parasites of the gastrointestinal tract. A variety of nematodes is usually present as mixed infections. The most important species are those found in the abomasum and small intestine. This includes; Haemonchus, Cooperia, Ostertagia, Bunostomum, Trichostrongylus, Oesophagostomum and Nematodirus [8]. Clinical diagnosis of GI strongylosis is difficult, since the signs are not pathognomonic. however, diagnosis of gastrointestinal nematode infections plays a major role in investigating parasite epidemiology. The ante mortem diagnosis of nematode infections in livestock had based on the detection of nematode eggs or larvae in the faeces by microscopic examination using the methods of flotation and/or larval culture. Quantifying of the egg per gram of feces is the best way of estimating parasite loads [9].

Although considerable work has been done on gastro intestinal parasite of sheep in many parts of Ethiopia, there was no previous study conducted on prevalence and associated risk factor on ovine gastrointestinal nematodes in the present study area, where mixed crop livestock production system is the main form of agriculture. On the other hand, knowing the current situation of GIT nematode in the area could be the basis for all possible actions including its control and prevention. Consequently, the objective of present study was carried out to determine the prevalence of ovine gastrointestinal nematodes and associated risk factor of sheep in jigjiga woreda eastern Ethiopia. To obtain reference point data so as to design effective strategic treatment for parasite infected sheep and creating farm awareness how to control and prevention parasitic losses.

\section{Material and Methods}

\section{Study Area}

The study was conducted from November 2015 to April 2016 in jigjiga woreda fafan zone Somali regional state eastern Ethiopia located at $630 \mathrm{~km}$ away from Addis Ababa south east and above sea level 1803meter elevation. Temperature of the area is generally high all the year round with mean minimum and maximum values being around $200 \mathrm{C}$ and 350C, respectively. The mean annual rainfall is $660 \mathrm{~mm}$ and bimodal. The type of farming is mixed crop agriculture and the type of livestock production systems in the area included extensive, semi-intensive and intensive type but predominantly it is extensive type and the livestock population in and around Jijiga currently 6 million cattle and 1.5 million camels. They are 1.316 million sheep and 548,000 goats in jijiga woreda [10].

\section{Study Design and Study Methodology}

A cross-sectional type of study was used for determination GIT nematode prevalence of sheep through coprological examination. The fecal sample was collected from different age, sex and body condition within two seasons (dry and wet) of year. Age was determined for both sexes based on dental eruption. Those animals with the age of less than one year were considered as young while those greater than or equal to one were considered as adults according to the classification of age groups according to [11]. Body condition scoring of sampled animals was carried out according to the method described by [12] and categorized into three scores as poor, medium and good.

\section{Study Animal Population}

The study populations were local sheep kept under traditional extensive management system consisting of different age, sex and body condition groups from six randomly selected peasant associations in jijiga woreda

\section{Sampling Method and Sample Size Determination}

A total six peasant associations were randomly selected and different proportions of samples were collected from each PAs and the household and the fecal samples were collected from individual study animals using simple random sampling. The sample size was determined by the formula described by Thrusfield [13]. Accordingly, at $95 \%$ confidence level and precision of 5\% the total sample size was determined to be 384 . Since there was, not investigation carried out previously in the study area.

$$
n=\frac{1.962 * P_{e x p}\left(1-P_{e x p}\right)}{d^{2}}
$$

Where: $\mathrm{n}=$ sample size $\mathrm{P}_{\exp }=$ minimum expected prevalence $=50 \% 1.96=$ the value of $Z$ at $95 \%$ confidence interval $d=$ desired accuracy level at $95 \%$ confidence interval.

\section{Parasitological Study}

A new faecal sample of approximately 10gram was collected directly from the rectum of 384 sheep using gloved finger. Each sample was clearly labeled with animal identification, date and place of collection. The faecal samples were placed in a universal bottle, labeled and $10 \%$ formalin was added to preserve parasite eggs and transported to Jijiga university Veterinary parasitology Laboratory for examination. Those samples, which were not examined within 24 hour of arrival at laboratory, were stored at +4 ${ }^{\circ} \mathrm{C}$ and examined the next day early in the morning.

The collected samples were subjected to qualitative flotation and quantitative McMaster egg counting parasitological techniques using saturated sodium chloride (specific gravity of 1.2) as flotation fluid described by Charles [14]. The eggs of different parasite species were identified using keys given by Soulsby [15]. Those samples found positive for gastrointestinal nematode was subjected to EPG counting to determine the number of eggs per gram of feces (EPG) and performed according to the procedure de- 
scribed by Urquhart [16]. The degree of infection was categorized as light, moderate and severe (massive) according to their egg per gram of faeces (EPG) counts. Egg counts from 50-799, 800-1200 and over 1200 eggs per gram of feces were considered as light, moderate and massive infection, respectively

\section{Data Management and Analysis}

The raw data was entered into Microsoft excel spreadsheet and analyzed using SPSS statistical software version 20. Descriptive statistics were used to quantify the problems and Pearson Chi-square test was used to compare association between independent variables (sex, age, body condition scores and season) and parasitism. Confidence interval was set at $95 \%$ and statistically significant association between variable was considered to exist if the computed p-value is less than 0.05 . The prevalence was calculated by dividing the number of positive animals by the total number of animals examined and times 100. Percentage (\%) to measure prevalence (Table 1).

Table 1: The prevalence gastro intestinal nematode of sheep at different peasant association in study area.

\begin{tabular}{|c|c|c|c|c|}
\hline $\begin{array}{l}\text { Peasant } \\
\text { Associa- } \\
\text { tion }\end{array}$ & $\begin{array}{l}\text { No. Exam- } \\
\text { ine }\end{array}$ & $\begin{array}{l}\text { No. Posi- } \\
\text { tive }\end{array}$ & $\begin{array}{c}\text { Prevalence } \\
\text { (\%) }\end{array}$ & p-value \\
\hline Kebele 12 & 55 & 32 & 58.1 & \multirow{7}{*}{0.856} \\
\hline Kebelle 07 & 59 & 36 & 61 & \\
\hline Kebele 17 & 64 & 38 & 59.3 & \\
\hline Kebele 05 & 66 & 44 & 67 & \\
\hline Kebele 09 & 68 & 52 & 76.4 & \\
\hline Gabrile & 72 & 55 & 76.3 & \\
\hline Total & 384 & 257 & 66.9 & \\
\hline
\end{tabular}

Result

The general prevalence of ovine gastrointestinal nematodes was $66.9 \%$ (257/384). A prevalence of $69.6 \%$ in females, $63.1 \%$ in males, $58.9 \%$ in adult, $82.8 \%$ in young, $86.4 \%$ in poor, $70 \%$ in medium and $50 \%$ in good, $52.8 \%$ in dry season and $75.5 \%$ in wet season were detected. Of all the sheep examine in the six-peasant association sample from kebele 09 (76.4\%) showed that higher prevalence Git nematode and low prevalence Git nematode in kebele 12 (58.1\%) overall prevalence no significant difference.

Table 2: The prevalence of particular ovine gastro intestinal nematode infection in the area.

\begin{tabular}{|c|c|c|c|}
\hline $\begin{array}{c}\text { Type of para- } \\
\text { site eggs }\end{array}$ & No. Examined & No. Positive & $\begin{array}{c}\text { Prevalence } \\
\text { (\%) }\end{array}$ \\
\hline Strongyle & 384 & 210 & 54.6 \\
\hline Strongliodes & 384 & 18 & 4.7 \\
\hline Trichuris & 384 & 9 & 2.3 \\
\hline Mixed & 384 & 20 & 5.2 \\
\hline Total & 384 & 257 & 66.9 \\
\hline
\end{tabular}

The predominance gastro intestinal nematode identified in study area were strongyle, mixed type, srongloide and, trichuris with over all prevalence $54.6 \%, 5.2 \%, 4.7 \%$ and $2.3 \%$ respectively in (Table 2). Mixed nematode of egg was notices in some of the sample examined beside the single type of nematode egg with over all prevalence $5.2 \%$. Among this, the strongyle type egg and trichuris live together most of the time with over all prevalence $2.3 \%$ and the strongyle type egg and srongloide live together with over all prevalence $1.8 \%$ in (Table 3 ). Adult and young animal were found to be infested with prevalence $63 \%$ and $83 \%$ respectively with significant different $(\mathrm{p}<0.05)$. The female and male were found to be infested with a prevalence $69.6 \%$ and $63.1 \%$ respectively but there was no significant variation $(p>0.05)$ between the two sex. Infection prevalence was significantly higher in animal with poor body condition score $(\mathrm{p}<0.05)$ the overall infection prevalence according to body condition grade $86.4 \%, 70 \%$ and $52.8 \%$ with poor, medium and good respectively. The dry and wet prevalence of gastro intestinal nematode infection of sheep showed that there was statistically significant variation between the two season $(\mathrm{p}<0.05)$ the higher infection prevalence was record during wet season with $77.1 \%$ and slightly lower in dry season with 61\% (Table 4).

Table 3: Mixed type of gastro intestinal nematode egg in sheep.

\begin{tabular}{|c|c|c|c|}
\hline Nematode type egg & No. Examine & No. Positive & $\begin{array}{c}\text { Prevalence } \\
\text { (\%) }\end{array}$ \\
\hline $\begin{array}{c}\text { Strongyle }+ \text { stron- } \\
\text { gloide }\end{array}$ & 384 & 7 & 1.8 \\
\hline Strongyle+trichuris & 384 & 9 & 2.3 \\
\hline $\begin{array}{c}\text { Strongyle+trichu- } \\
\text { ris+strongliode }\end{array}$ & 384 & 4 & 1.0 \\
\hline Total & 384 & 20 & 5.2 \\
\hline
\end{tabular}

Table 4: Prevalence of ovine gastro intestinal nematode by sex age body condition and season.

\begin{tabular}{|c|c|c|c|c|c|}
\hline $\begin{array}{c}\text { Risk } \\
\text { factor }\end{array}$ & $\begin{array}{l}\text { No. Ex- } \\
\text { amine }\end{array}$ & $\begin{array}{l}\text { No. Posi- } \\
\text { tive }\end{array}$ & $\begin{array}{c}\text { Preva- } \\
\text { lence } \\
(\%)\end{array}$ & $X^{2}$ & P_Value \\
\hline \multicolumn{4}{|c|}{ Age } & \multirow{4}{*}{26.97} & \multirow{4}{*}{0.00} \\
\hline Adult & 256 & 161 & 63 & & \\
\hline Young & 128 & 106 & 83 & & \\
\hline Total & 384 & 257 & 66.9 & & \\
\hline \multicolumn{4}{|c|}{ Sex } & \multirow{4}{*}{7.5} & \multirow{4}{*}{0.112} \\
\hline Male & 160 & 101 & 63.1 & & \\
\hline Female & 224 & 156 & 69.6 & & \\
\hline Total & 384 & 257 & 66.9 & & \\
\hline \multicolumn{4}{|c|}{ BCS } & \multirow{5}{*}{30.5} & \multirow{5}{*}{0.00} \\
\hline Poor & 74 & 63 & 85.1 & & \\
\hline Medium & 170 & 121 & 71.1 & & \\
\hline Good & 140 & 73 & 52.1 & & \\
\hline Total & 384 & 257 & 66.9 & & \\
\hline \multicolumn{4}{|c|}{ Season } & \multirow{4}{*}{11.21} & \multirow{4}{*}{0.024} \\
\hline Dry & 244 & 149 & 61 & & \\
\hline Wet & 140 & 108 & 77.1 & & \\
\hline Total & 384 & 257 & 66.9 & & \\
\hline
\end{tabular}


Egg count from 50 to 799 light from 800 to 1200 moderate and above 1200 souls by [15] A total of 257 fecel sample that were positive by qualitative (flotation)parasitological techniques were subjected to EPG count or McMaster counting techniques accordingly $91(35.4 \%), 90(35 \%)$ and $76(29.5 \%)$ light, moderate and heavy respectively (Table 5). This study has shown that the sex has no statically significant different with epg ( $p>0.05)$ slightly higher in female than male. But the difference in the degree of epg between young and adult sheep was statically significant $(\mathrm{p}<0.05)$ young animal were found to be harbor substantial parasite load than adult and also the parasite burden is highly related to the body condition of the animal and the different was significant with epg $(p<0.05)$. This can be shown by the fact that severely affected animal was found highly in number with poor body condition than good body condition (Table 6). The difference in the degree of epg between dry and wet season was significant association $(p<0.05)$. Fecal egg harvest increased during rainy season as compare to dry season.

Table 5: Degree of severity of nematode in infected sheep based on fecal in study area.

\begin{tabular}{|c|c|}
\hline Intensity of Infection & Examine no. Sample \\
\hline Light & $91(35.4 \%): 50-799$ egg \\
\hline Moderate & $90(35 \%): 800-1200$ egg \\
\hline Heavy & $76(29.5 \%):$ greater than 1200 egg \\
\hline Total & $257(66.9 \%)$ \\
\hline
\end{tabular}

Table 6: Degree of gastro intestinal nematode infection with different risk factor (epg) category \%.

\begin{tabular}{|c|c|c|c|c|c|c|}
\hline \multirow{2}{*}{$\begin{array}{l}\text { Risk } \\
\text { fac- } \\
\text { tor }\end{array}$} & \multicolumn{6}{|c|}{ Degree of infestation } \\
\hline & & $\begin{array}{l}\text { Light } \\
(\%)\end{array}$ & $\begin{array}{l}\text { Moder- } \\
\text { ate (\%) }\end{array}$ & $\begin{array}{c}\text { Heavy } \\
(\%)\end{array}$ & $\mathbf{X}^{2}$ & $\begin{array}{c}\text { p_val- } \\
\text { ue }\end{array}$ \\
\hline \multirow{2}{*}{ Sex } & Female & 55 (35.2) & $59(37.8)$ & $42(26.9)$ & \multirow{2}{*}{3.59} & \multirow{2}{*}{0.31} \\
\hline & Male & $36(35.6)$ & $31(30.6)$ & $34(33.7)$ & & \\
\hline \multirow{2}{*}{ Age } & Young & $28(26.4)$ & $34(32.0)$ & $44(41.5)$ & \multirow{2}{*}{36.4} & \multirow{2}{*}{0.00} \\
\hline & Adult & $63(41.7$ & $56(37.0)$ & 32 (21.1) & & \\
\hline \multirow{3}{*}{ Bcs } & Poor & $13(21)$ & $17(27)$ & $33(52.4)$ & \multirow{3}{*}{53.4} & \multirow{3}{*}{0.00} \\
\hline & $\begin{array}{l}\text { Medi- } \\
\text { um }\end{array}$ & $49(40.4)$ & $41(34)$ & $31(27)$ & & \\
\hline & Good & $29(40)$ & $32(44)$ & $12(16.4)$ & & \\
\hline \multirow{2}{*}{$\begin{array}{l}\text { Sea- } \\
\text { son }\end{array}$} & Dry & $57(38.2)$ & $55(37)$ & $37(25)$ & \multirow{2}{*}{14.5} & \multirow{2}{*}{0.002} \\
\hline & Wet & 34 (31.4) & 35 (32.4) & 39 (36.1) & & \\
\hline
\end{tabular}

\section{Discussion}

The present study exposed that the existence of major gastro intestinal nematode parasites of ovine with over all prevalence of $66.9 \%$ originating from this study area. Which were being parasitized at least by one type of gastrointestinal nematodes. This finding agrees with previous studies by coprological examination in some areas of Ethiopia 64.8\% Abdurezaq [17];68.1\% Diriba \& Birhanu [18]; 68.4\% Lemma [19]. Contradictory outcomes were reported in different parts of the country including $97.03 \%$ strongyles type, $45.22 \%$ strongyloidiasis and $30.25 \%$ Trichuris species in eastern part of Ethiopia Abebe \& Eseyas [20] 98.9\% in southern Ethiopia Amenu [21], 24.7\% of overall prevalence in western Oromiya, Ethiopia Takele [22].

This difference could be owing to the sample size considered and types of methods utilized and the prevalence varies greatly from region to region corresponding to ecological and climatic diversity as well as the existing host ranges within flock [23]. Hence the current prevalence of gastrointestinal nematodes 54.3\%, strongyle, $4.7 \%$ srongyloide $2.3 \%$ trichuris. This results agreement with reports of previous studies conducted in Ethiopia, as $52.3 \%$ strongyles, $6.8 \%$ strongyloide, $1.8 \%$ trichuris in gursum by Abdurezaq [17]. $56.6 \%$ strongyles, $8.2 \%$ strongyloides and 5\% trichuris in Debre Zeit Tigist [24]. 66.6\% strongyles and 3.3\% Trichuris species in Bedele Temesgen [25]. 64\% strongyles type and 7.4\% strongyloides and 3.7 Trichuris Diriba \& Birhanu [18] in asella, south eastern Ethiopia.

The current study was shows high prevalence of strongyle than stongloide and trichuris during examination of fecal slide. This finding agrees with a number of findings obtained by different investigators in which Strongyle species were overriding by Tigist \& Temesgen [24,25]; Abdurezaq [17] who reported prevalence of $56.6 \%, 66.6 \% 52.3 \%$ respectively. Hence, strongyles are gastrointestinal nematodes of greatest importance in sheep, and causes serious direct and indirect losses in most parts of the country according to the study carried out by Dagnachew, Kumsa, Diriba \& Birhanu \& Regassa $[7,18,26,27]$. This study showed that strongyles were the most conspicuous among those gastrointestinal nematode parasites of sheep. The high prevalence of strongyles may be due to the existence of host range in jigjiga area for existence and transmission of the parasite and suitable environmental condition for L3.

The prevalence of Strongyloides species in the present study was $4.7 \%$ which an agrees with the report of Abdurezaq [17] from gursum \& Tigist from Debre Zeit, who reported the prevalence of Strongyloides species as $6.8 \%$ and $8.2 \%$, correspondingly. The prevalence of Trichuris species in the present study was $2.3 \%$ and this finding was in route with work of Tigist, Temesgen Ragassa, \& Diriba \& Birhanu $[7,18,24,25]$ with prevalence of $5 \%, 3.3 \%, 4.5 \%$ and $3.7 \%$, respectively.

The current finding however was lower as compared to $30.3 \%$ from Eastern part of Ethiopia by Abebe \& Eseyas [20]. In addition, this agrees with the idea of Urquhart [16], which indicates only young are more susceptible to these parasites while adults usually develop certain immunity and the presence of resistance for Trichuris in sheep over eight months and not usually severe enough to cause clinical disease. A clinical sign was showed mainly in the young and appear only in case of severe infection. The present study has shown that the presence of mixed infection of two or more nematodes genera in single host. This agrees with 
the findings of other researchers in the country Tefera, Kumsa \& Abdurezaq $[17,27,28]$.

In this study when comes to the sex there were no significant variation was observed between male and female despite slightly higher infection noticed in female sheep with $69.3 \%$ female and $63.1 \%$ male respectively. There was no statistical association between sex and prevalence of gastro intestinal nematodes agree with that of Abdurezaq, Regassa \& Ghanem [7,17,29]. This also agrees with report by Assefa \& Sissay [30]. This is due to equal exposure of both sexes, and they are from similar agro-ecology. The variation may occur in the intensity of infection due to post-parturient parasite rise in lambed sheep. Until now, it disagrees with other reports Urquhart \& Keyyu [7,31] the females are more prone to parasitism during pregnancy and per-parturient period due to stress and decreased immune status. In the present study were finding that young more repeatedly infected than adult sheep. The statically significant difference $(\mathrm{P}<0.05)$ was recorded between the two age groups. This might be due to new born and younger sheep lack of strong immunity as in the adults. The possible explanation is that in adult sheep, after primary infection, rapid solid immunity is developed. In fact, sheep continually exposed to infection are at low risk provided the rate of acquisition of infective larvae is sufficient to stimulate satisfactory response, and no cause of clinical illness Diriba \& Birhanu [18].

The pregnant or lactating ewes became the major source of infections for the newborn lambs. In the same manner, other studies in Africa have shown that the age and immune status of the host animal have significant influences on nematode egg output Magona \& Musisi [32]. In this study, a significant difference was observed in prevalence of nematode infection in relation to body condition score. Where a higher prevalence of gastrointestinal nematodes parasites was recorded in poor and moderate body as compared to animals with good body condition. This finding agrees with Abdurezaq, Negasi \& Gonfa $[17,33,34]$. In the present study significant difference $(\mathrm{p}<0.05)$ was recorded between the prevalence and season of year. High prevalence was observed during rainy seasons as compared to dry seasons which agrees with Keyyu [35]. This is because renewal of rainy season is the most favorable period for larval development and transmission on pasture by Abdurezaz [17]. In dry and hot areas, except in irrigated or other permanently wet pasture the transmission is restricted to the rainy season and the only means of carry-over of infection from one rainy season to another is through animals harboring adult worms and/or arrested (hypo biotic) larvae by Chiejina. Survival and transmission of free-living stage of nematode parasites is influenced by micro-climatic factors within the faecal pellets and herbage which agrees with Urquhart [7].

The degree (severity) of parasitic infestation was determined from the total fecal egg count (EPG). A determination was made to see the existence of difference in degree of parasitic infestation with the variation of age, sex, body condition and season. The present results for relative severity of parasitic infestation in studied animals were found 91(35.4\%), 90 (35\%), and 76(30\%) light, moderate and massive respectively. It is an agreement with study in and around Bako Town, Western Ethiopia where $29.6 \%$, $54.1 \%$ and $16.6 \%$ were lightly, moderately and massively infested, respectively by Ayele [36], 38.3\% were lightly, 32.5\% were moderately and $26.2 \%$ were massively affected Abdurazaq [17] gursum woreda. In the current study the mean EPG was slightly greater in females than males but there was not significantly different between the two sex which agrees with that of Tefera \& Bikila [28,37] in Ethiopia; Keyyu [31] in southern Tanzania. In the present study, the EPG were high in young with significant difference from adult age group. This follows with the result reported by Abdurezaq, Sissay \& Bikila $[17,37,38]$ Eastern Ethiopia. Who suggested that younger animals were more prone to infection as compared to old ones?

This observation is disagreement with preceding works in Ethiopia and Kenya Githigia [39] that stated no association of degree of EPG and age of the animals as well as from semi-arid parts of Kenya that reported higher intensity of EPG in older sheep Waruru [40]. In the current finding, EPG were high in poor than good and medium body condition and significantly different from good body condition. This result corresponds with reports of Keyyu \& Van Wyk $[35,41]$. EPG exaggerated by season with significant rise in wet season. Correspondingly, seasonal variations in nematode fecal egg counts, which followed pattern of seasonal rainfall, were reported from different studies in the country Fikru, Sissay \& Abdurezaq $[17,38,42]$. Related to the present result, seasonal influences on worm faecal egg counts were reported in areas with distinct rainy and dry seasons in Kenya Nginyi, Tanzania Keyyu \& Qamar [35,43,44] described the role of meteorological data like humidity, rainfall and temperature which was correlated with the occurrence of the parasitic disease. The effect of seasons on EPG was significant $(\mathrm{P}<0.05)$. EPG started to increase in wet season to reach the highest level when the rainfall was highest. Subsequently, the EPG decreased during the dry season Sissay [38]. This is because of the nematode (L3) larvae were greatest during wet season by Ahmed [45].

\section{Conclusion and Recommendation}

In the present study, the overall prevalence of gastro intestinal nematodes were $66.9 \%$ in sheep. The main GIT nematodes parasites identified were strongyle, strongyloides and trichuris spp. Finally, nematodes are one of gastrointestinal parasite were prevalent in jijiga Woreda and sheep are infected with varied gastrointestinal nematodes that can seriously affect the health and productivity of the animals without shows clinical sign. These parasites affected all age and sex groups. Moreover, Age, body condition and seasonal changing aspects are greatest obvious risk factors related with gastrointestinal nematode infection. Besides, weak status of animal health services and lack of proper management, deficiency public awareness, higher host range and deficient of nutritional supplementation all over a year. Extensive type of production system mostly practices with mixed crop livestock agriculture system. 
Therefore, situate all the above condition the following recommendation forwarded

a. Separating the most susceptible young animals from adults, which is a possible source of infection.

b. Strategic use of anthelmintic and good management should be practiced Detailed study should be conducted to clearly identify parasitic fauna using faecal culture and postmortem examination in the study area.

c. The treatment should be based on laboratorical finding in order reduce anthelmintic drug resistance and avoid treat animal without prescription by veterinarian.

d. During the control and treatment of sheep gastro intastinal nematodiasis; age, season, body conditions should be considered as potential risk factors for the occurrence of the disease.

e. Treat sheep with broad spectrum anthelminthic at the beginning of rain season and at the end of dry season to reduce the worm burden and minimize pasture contamination with larvae, and treat flock with special consideration to those sheep in poor condition rather than individual animal separately

\section{Acknowledgement}

Firstly, of all I would have a great pleasure to thank my advisor Dr. Nugussu Fasil for his unforgettable guidance, devotion of time and for his suggestion to correct this paper. I would like to thank from depth of my heart to all my family and my friend abdurezaq Mohammed and shazali Mohammed for his tiresless help and support me at any time with experience.

\section{References}

1. Tony W (2007) The veterinary epidemiology and economics research unit (VEERU), School of agriculture, policy and development. The University of reading, United Kingdom.

2. Food and Agriculture Organization FAO (2010) Breeding strategies for sustainable management of animal genetic resources. Animal Production and Health Guidelines, No.3.Food and Agriculture Organization of the United Nations, Rome, Italy.

3. Kefyalew A, Tegegne F (2012) The effect of climate change on ruminant livestock population dynamics in Ethiopia. Bahir Dar University, college of agriculture and environmental sciences, department of animal production and technology, Bahir Dar, Ethiopia and Mizan-Tepi University, college of agriculture and natural resources, department of animal sciences, Ethiopia, Livestock Research for Rural development 24: 10 .

4. Samson, Frehiwot M (2010) Prevalence of Small Ruminant Trypanosomosis and Tsetse Fly Challenge in Upper Didessa Vally, Ethiopia. Adami-Tullu Agriculture Research Center, Ziway, Ethiopia, pp. 215.

5. Central Statistical Authority (2011) Agricultural sample survey 20102011. Report on livestock and livestock characteristics. Statistica Bulletin, Addis Ababa, Ethiopia.

6. Sisay M (2007) Helminth Parasites of Sheep and Goats in Eastern Ethiopia. Epidemiology and Anthelmintic Resistance and its Management. Faculty of Veterinary Medicine and Animal Science. Department of Biomedical Sciences and Veterinary Public Health Division of Parasitology and Virology Uppsala Sweden Doctoral thesis Swedish University of Agricultural Sciences p. 11-12.
7. Regassa F, Teshale S, Reta D, Yosef K (2006) Epidemiology of gastrointestinal parasites of ruminants in Western Oromia, Ethiopia. Int J Appl Res Vet Med 4(1): 51- 57.

8. Hutchinson G (2009) Nematode Parasites of Small Ruminants, Camelids and Cattle diagnosis with emphasis on anthelmintic efficacy and resistance testing formerly at Elizabeth Mcarthur agricultural Institute, New South Wales, department of primary Industries p. 1- 61.

9. Roeber F, Jex R, Gasser R (2013) Impact of gastrointestinal parasitic nematodes of sheep and the role of advanced molecular tools for exploring epidemiology and drug resistance-an Australian perspective. The University of Melbourne, Australia, Journal of pharmaceutical policy and practice, 6: 153. 13. Pugh, D.G. Sheep and Goat Medicine ( $1^{\text {st }}$ edn), College of Veterinary Medicine, Auburn University, Australia.

10. Somali Regional Pastoral and Agro-Pastoral Research Institute (2003) Small Ruminant Research Strategy. Jijiga, Ethiopia, p. 40.

11. Kumsa B, Tolera A, Nurfeta A (2010) Comparative efficacy of seven brands of albendazole against naturally acquired gastrointestinal nematodesin sheep in Hawassa, Southern Ethiopia. Turk J Vet Anim Sci 34: 417-425.

12. Kripali K, Rajput S, Jitendra V, Shivan V, Pritee G (2010) Prevalence of helminthes in small ruminants in Tarai region of Uttarakhand. Veterinary World 2: 265-266.

13. Thrusfield M (2007) Veterinary Epidemiology. Blackwell Science Limited, USA, pp. 180-181.

14. Charles M (2006) Diagnostic veterinary Parasitology. ( $3^{\text {rd }}$ edn), Stilous Elsevier science.

15. Soulsby E (1986) Helminthes arthropods and protozoa of domestic animals ( $7^{\text {th }}$ edn), Bailliers Tindall, London, UK, pp. 247-250.

16. Urquhart M, Armour J, Duncan L, Dunn,M, Jennings W (1996) Veterinary parasitology, $\left(2^{\text {nd }} e d n\right)$, The Faculty of Veterinary Medicine, University of Glasgow Scotland, pp. 4-137.

17. Abdurezaq M, Haimanot D, Tadele K, Tilahun Z, Girma K (2015) gastro intestinal nematode of ovine in gursum woreda DVM thesis WU CVM wollega Ethiopia.

18. Diriba L, Birhanu A (2013) Prevalence of ovine gastrointestinal nematodes in and around Asella, South Eastern Ethiopia Asella Regional Veterinary Laboratory P. 0. Box 212, Asella, Ethiopia. J Vet Med Anim Health p. 223-228.

19. Lemma D, Biruhtesfa A, Surafel K (2015) Prevalence of Gastrointestinal Nematodes of Small Ruminants in and Around Arsi Negele Town, Ethiopia School of Veterinary Medicine, Hawassa University, AmericanEurasian Journal of Scientific Research 10(3): 121-125.

20. Abebe W, Esayas G (2001) Survey of ovine and caprine intestinal helminthosis in eastern part of Ethiopia during the dry season of the year. Rev Vet Med 152(5): 379- 384.

21. Amenu A (2005) Epidemiology of gastrointestinal tract nematodiasis of small ruminants in three different agro-ecological zones of Southern Ethiopia. Master of Science Thesis in Tropical Veterinary Epidemiology, School of Graduate Studies, Addis Ababa University, Ethiopia, p. 86.

22. Takele S, Yacob H, Getachew T (2013) Epidemiology of gastrointestinal nematodes of Horro sheep in Western Oromiya, Ethiopia. Addis Ababa University, College of Veterinary Medicine and Agriculture, Department of Pathology and Parasitology, Debre Zeit, Ethiopia.

23. Njau C, Scholtens G, Dasali O (1990) Parasites of the sheep. International Livestock Centre for Africa, Debre-Zeit station, Ethiopia. Prev Vet Med 9: 267- 277.

24. Tigist $\mathrm{T}$ (2008) Gastrointestinal parasitosis of small ruminants in and around Debre Zeit. DVM thesis HU, FVM, Haramaya, Ethiopia. 
25. Temesgen $T$ (2008) Study on prevalence of ovine gastrointestinal parasite in and around Bedele DVM thesis, HU, FVM, Haramaya, Ethiopia.

26. Dagnachew S, Amamute A, Temegen W (2011) Epidemiology of gastrointestinal helminthiasis of small ruminants in selected sites of North Gondar zone, Northwest Ethiopia. Ethiopia, Vet J 15(2): 57-68.

27. Kumsa B, Tadesse T, Sori T, Dugum R, Hussen B (2011) Helminths of sheep and goats in Central Oromia (Ethiopia) during the dry season. J Anim Vet Adv 10(14): 1845- 1849.

28. Tefera M, Batu G, Bitew M (2011) Prevalence of Gastrointestinal Parasites of Sheep and Goats in and Around Bedelle, South-Western Ethiopia. Internet J Vet Med 8: 2.

29. Ghanem M, Naser H, Abdelkader H, Heybe A (2009) An epidemio coprological study of protozoan and nematode parasites of ruminants in tropical semi-arid district of Somali 1 and (Northern of Somalia). Vet Med J 3rd Sci Congress pp. 768-787.

30. Assefa D, Sissay L (1998) Preliminary investigation on the seasonal occurrence of parasites around Sheno: In: $5^{\text {th }}$ national conference of society of animal production. Addis Ababa Ethiopia, pp. 123-137.

31. Keyyu D, Kassuku A, Kyvsgaard C, Willingham W (2003) Gastrointestinal nematodes in indigenous zebu cattle under pastoral and nomadic management systems in the lower plain of Southern highlands of Tanzania. Vet Res Commun 27(5): 371-380.

32. Magona W, Musisi G (2005) Influence of age, grazing system, season and agro-climatic zone on the prevalence and intensity of gastro intestinal stronglosis in Ugandan goats. Small ruminant research.

33. Negasi W, Bogale B, Chanie M (2015) Helminth parasites in small ruminants: prevalence, species composition and associated risk factors in and Around Mekelle Town, Northern Ethiopia. Europ J Biol Sci 4(3): 91-95.

34. Gonfa S, Basaznew B, Achenef M (2007) An Abattoir Survey on Gastrointestinal Nematodes in Sheep and Goats in Hemex-Export Abattoir, Bishoftu (Debre Zeit), Central Ethiopia. J Adv Vet Res 3: 60-63.

35. Keyyu DNC, Kyvsaard NJ, Monrad J, Kassuku AA (2005) Epidemiology of gastrointestinal nematodes in cattle on traditional, small-scale dairy and large-scale dairy farms in Iringa district, Tanzania. Vet Parasitol 127: 285-294.
36. Ayele G, Nugusa F, Tadesse B (2014) Prevalence and associated risk factors of major sheep gastro intestinal parasites in and around Bako Town, Western Ethiopia. Livestock Research for Rural Development 26: 10.

37. Bikila E, Yeshitla A, Worku T, Teka F, Benti D (2013) Epidemiology of Gastrointestinal Parasites of Small Ruminants in Gechi District,Southwest Ethiopia. Advances in Biological Research 7(5): 169-174.

38. Sisay M, Uggla A, Waller J (2006) Prevalence and seasonal incidence of nematode parasites and fluke infections of sheep and goats in eastern Ethiopia. Trop Anim Health Prod p. 39.

39. Githigia M, Thamsborg M, Maingi N, Munyua K (2005) The epidemiology of gastrointestinal nematodes in Goats in the low potential areas of Thika District, Kenya. Bull Anim Health Prod Afr 53(1): 5-12.

40. Waruru M, Mutune N, Otieno O (2005) Gastrointestinal parasite infections of sheep and goats in a semiarid area of Machakos District, Kenya. Bull Anim Health Prod Afr 53(1): 25-34.

41. Van Wyk A, Hoste H, Kaplan M, Besier B (2006) Targeted selective treatment for worm management How do we sell rational programs to farmers? Vet Parasitol 139: 336- 346.

42. Fikru R, Teshalem S, Reta D, Yosef K (2006) Epidemiology of Gastrointestinal Parasites of Ruminants in Western Oromia. Ethiopia, Int J Appl Res Vet Med 4(1): 51-57.

43. Nginyi M, Duncan L, Mello J (2001) Epidemiology of parasitic gastrointestinal nematode Infections of ruminants of smallholder farms in central Kenya. Res Vet Sci 70(1): 33- 39.

44. Qamar MF, Maqbool A, Khan MS, Ahmad N, Muneer MA (2009) Epidemiology of Haemonchosis in sheep and goats under different managemental conditions. Vet World 2: 413-417.

45. Ahmed M (2010) Gastrointestinal nematode infections in small ruminants: Epidemiology, Anthelmintic efficacy and the effect of wattle tannins. Animal Science Discipline of Animal and Poultry Sciences, School of Agricultural Sciences and Agribusiness University of KwaZulu-Natal Alabama p. 88-89.

Your next submission with Juniper Publishers
will reach you the below assets
- Quality Editorial service
- Swift Peer Review
- Reprints availability
- E-prints Service
- Manuscript Podcast for convenient understanding
- Global attainment for your research
- Manuscript accessibility in different formats
( Pdf, E-pub, Full Text, Audio)
- Unceasing customer service
Track the below URL for one-step submission
https://juniperpublishers.com/online-submission.php


